\title{
Nutrition education: higher education
}

\section{By Mary E. Lonergan and Doreen A. Parry, Queen Margatet College, Clerwood Terrace, Edinburgh}

Good or poor nutrition education begins in early life. Often reinforced by misguided parental threats and entreaties, the preschool child, within the framework of personal preference, usually displays uncritical acceptance of family eating patterns. When he first enters school he regards his own eating habits, whether the emphasis is on pie and chips, meat and two vegetables or on vegan fare, as the norm. His attitudes are influenced to a greater or lesser extent by formal and informal educational techniques at school. Thus students reaching higher education already possess well-established eating patterns, some knowledge of the significance of foods and often a sense of complacency in that, from personal experience, 'everyone knows about foods and what they do'! Some, probably less complacent as a result, will already have encountered nutritional problems such as obesity.

In Scotland, higher education falls within four sectors: local authority colleges, colleges of education, central institutions and the universities. Nutrition education in the last is considered separately. This paper relates only to the first three sectors in general and to colleges offering certain vocational courses in particular. These include courses in home economics, and national diploma courses in catering, life sciences (nursing) and dietetics. The student following national diploma and home economics courses is concerned primarily with nutrition in the healthy individual, although sufficient knowledge of therapeutic nutrition is required to allow the provision of advice of a general nature and the recognition of the need for specialist assistance. The student nurse and student dietitian are concerned with both normal and therapeutic nutrition. As future practitioners and educators, for all these students, a study of nutrition makes an important contribution to professional training. Educational programmes should aim to provide sound theoretical knowledge combined with realistic attitudes and awareness of factors influencing food choice and food acceptance. Some factors which seem to the authors to be of importance in devising learning programmes are considered.

For too long nutrition has been defined as a study of the digestion, absorption and utilization of nutrients. Such an academic study of the principles of nutrition may well provide a satisfying intellectual challenge, particularly for the student whose background knowledge of science is sound. But for the practitioner and educator, such a study is, in isolation, unsatisfactory. Without application of nutritional principles in practical and realistic situations, it could even be suggested that parsley and watercress are good dietary sources of ascorbic acid and 
iron respectively! In addition, it must be admitted that tables of food composition, although of considerable assistance, are not sacrosanct.

Perhaps the first practical point to emphasize is that, apart from the eccentric or the nutritionally dedicated, people eat foods rather than nutrients. So that interest and awareness may be more readily aroused, illustrations used in teaching these groups of students are linked to the sedentary female aged 18-55 years. With the recommended daily intake of energy of $9.2 \mathrm{MJ}(2200 \mathrm{kcal})$, the recommended daily intake of $55 \mathrm{~g}$ protein is demonstrated together with energy from fat at the $25 \%$ and $40 \%$ levels respectively $(6 \mathrm{I}$ and $98 \mathrm{~g} / \mathrm{d}$ ). Appropriate adjustment of the carbohydrate content is made ( 356 and $275 \mathrm{~g} / \mathrm{d}$ ). For satisfactory nutrition, the need for the addition of vitamins, mineral elements and water is noted. (Such displays, once prepared, can be used on several occasions and may be photographed for use in future teaching programmes.) The obvious aim in showing nutrients as such is to create in the student awareness that people do not eat nutrients but a variety of foods, attractively prepared and presented, within the framework of meals and associated social connotations. However apparently nutritionally satisfactory a food or meal, nutritional value is nil unless it is eaten!

The next stage is to identify the problems of assessing an individual's food intake. The majority of students appear to find visual displays of food portions or realistic model foods of considerable assistance. To provide some ability to estimate food portions, $400 \mathrm{~kJ}$ (approximately $100 \mathrm{kcal}$ ) portions of selected foods are prepared (Table I). The scope of these visual presentations may be considerably extended if students are encouraged to calculate and weigh food portions and arrangements are made for photographic records to be prepared. Thus, it is hoped that the energy content of foods may be more readily appreciated.

In addition, the problems of estimating the energy content of foods actually eaten but all too frequently omitted from dietary records and histories (by accident or design!) may be emphasized by illustrations such as those shown in Table 2.

As an additional illustration of the problems of assessing energy intake, the 'invisible' fat content of portions of foods may be presented visually (Table 3 ).

Having established that foods rather than nutrients are of practical significance and that accurate assessment of food intake is difficult, the next stages involve a study of the factors which influence food choice and food acceptance. Since merely advising or even compulsion is unlikely to achieve success in the long term, it is at

Table I. Weights (g) of portions of common food items supplying $400 \mathrm{kF}$ energy

$\begin{array}{lr}\quad \text { Food } & \\ \text { Mill } & 147 \\ \text { Bread } & 38 \\ \text { Butter } & 13 \\ \text { Peas } & 152 \\ \text { Haddock } & 138 \\ \text { Beef } & 45 \\ \text { Potato } & 126 \\ \text { Chocolate (mills) } & 17\end{array}$


Table 2. Energy content of selected beverages and foods frequently omitted from dietary records

\begin{tabular}{|c|c|c|c|c|}
\hline \multirow[b]{2}{*}{ Beverage or food } & \multirow[b]{2}{*}{ Portion } & \multirow{2}{*}{$\begin{array}{c}\text { Weight } \\
\text { (g) }\end{array}$} & \multicolumn{2}{|c|}{ Energy content } \\
\hline & & & kJ & kcal \\
\hline $\begin{array}{l}\text { Beer (mild draught) } \\
\text { Beer (bitter) } \\
\text { Dry cider }\end{array}$ & $\begin{array}{l}\text { Half-pint } \\
\text { Half-pint } \\
\text { Half-pint }\end{array}$ & $\begin{array}{l}28_{4} \\
28_{4} \\
28_{4}\end{array}$ & $\begin{array}{l}290 \\
380 \\
420\end{array}$ & $\begin{array}{r}70 \\
90 \\
100\end{array}$ \\
\hline Dry sherry & Standard & 45 & 340 & 33 \\
\hline Whisky & Standard & 30 & 270 & 63 \\
\hline $\begin{array}{l}\text { Whisky } \\
\text { Roasted peanuts }\end{array}$ & Large & $\begin{array}{l}45 \\
25\end{array}$ & $\begin{array}{l}390 \\
610\end{array}$ & $\begin{array}{r}95 \\
14^{6}\end{array}$ \\
\hline Potato crisps & - & 25 & 590 & 140 \\
\hline Sugar & - & 25 & 410 & 99 \\
\hline Chocolate (mill) & - & 25 & 610 & 140 \\
\hline Bread & - & 28 & 300 & 72 \\
\hline Fried bread & - & 50 & 1120 & 268 \\
\hline
\end{tabular}

Table 3. Fat content of standard portions of some foods

$\begin{array}{lcc}\text { Food } & \text { Weight (g) } & \text { Fat content (g) } \\ \text { Mill } & 284.0 & 26.0 \\ \text { Bread } & 28 \cdot 4 & 0.5 \\ \text { Butter } & 28.4 & 23.4 \\ \text { Peas } & 85.2 & 0.0 \\ \text { Haddock } & 142.0 & 0.5 \\ \text { Beef } & 113.6 & 16.0 \\ \text { Sausage (pork) } & 113.6 & 31 \cdot 0\end{array}$

this point that the importance of selecting alternative dietary sources of a particular nutrient for the individual may be emphasized. For instance, in relation to dietary $\mathrm{Fe}$, provision should be made for people who are disinclined to include liver, kidney, meats and cocoa in the diet.

It is an advantage at this stage for students to have made a study of the organoleptic (sensory) appraisal of foods and to have had an opportunity to taste foods which are new and unfamiliar. Such studies provide greater appreciation of the effects of appearance, flavour and texture on food acceptance and of the suspicion and prejudice associated with unfamiliar foods which leads all too often to rejection. Should individual students become more adventurous in their attitude to foods, this can only be an advantage in their subsequent careers.

The majority of students reaching higher education (except those from areas with immigrant communities) are largely unaware of the social, psychological and economic factors influencing food choice and acceptance. The effects of culture, religion, eating patterns, psychological factors, fashions and faddism should be discussed, preferably in relatively small groups. To make discussions more meaningful appropriate practical exercises should be undertaken.

Such an approach to nutrition education is not intended to act as a substitute for a sound academic study of the principles of nutrition, which remains an essential feature of the subject. Rather it is to enable realistic application of knowledge to practical situations in relation both to the individual and to world food problems. 
For the four groups of students mentioned earlier, emphasis in different areas of the subject must vary. The national diploma students will usually become essentially the practitioners whereas, in addition, the home economist, nurse and dietitian are likely to act as educators. Thus for these three groups it will be necessary to discuss peoples' attitudes to food, methods by which food habits may be modified, to consider appropriate teaching techniques, to emphasize the need for the acquisition of skills in written, oral and visual communication and, particularly for the home economist and dietitian, to provide opportunities for the student to become proficient in the use of audio-visual aids.

The national diploma students are future managers and supervisors in the catering industry. Thus it is necessary to provide sound knowledge of the principles of nutrition, control of food portions in relation to nutrient intake and of production techniques which promote palatability of foods combined with nutrient retention. The ability to apply nutritional principles in catering for those with specific nutritional requirements, such as the obese, the diabetic, the vegetarian and the vegan, is also necessary. In what was previously known as the 'welfare' section of the catering industry, such knowledge and skills are of particular importance since so many of those for whom these students will eventually be responsible will be dependent on them for the provision of an optimal diet. In a recent survey carried out by the Hotel, Catering and Institutional Management Association (1974), Tomorrow's Managers, managers and supervisors in the catering industry considered that formal nutrition teaching in college courses had made a relatively small contribution to performance in their careers. However, this response, disappointing as it seems to the nutrition educator, might perhaps indicate that education has been more successful than appreciated, in that practical application of nutritional principles is made so much as a matter of habit as to become almost instinctive!

Career opportunities for home economists include teaching, lecturing, posts in industry, local authority and government departments and in broadcasting and journalism. The majority are required to give teaching or advice on nutritional topics. Courses in the social sciences as well as teaching programmes in nutrition and applied nutrition during their professional training enable home economists to apply their knowledge in assisting individuals, families and vulnerable groups with nutritional problems. For instance they are aware of the dietary problems of the elderly, reluctant to be considered 'old' or 'different', and often unwilling to sample unfamiliar foods however nutritionally desirable.

Although capable of either giving general advice or recognizing the need for specialist assistance when dealing with nutritional problems, as with the national diploma students, home economists are essentially concerned with nutrition in health. Hence for both these groups of students it is important in teaching the principles of nutrition to adopt a positive approach. This requires, for instance, that the role of ascorbic acid in collagen synthesis be stressed rather than its ability to prevent scurvy, and the significance of $\mathrm{Fe}$ as a component of the respiratory pigments rather than in the prevention of anaemia be emphasized. Effects of 
deficiency of a particular nutrient may thus be considered in context rather than as a threat (however interestingl) to those who eat insufficient foods of a particular group.

The principles of nutrition must also be studied by student nurses and dietitians, in particular by the latter. Therapeutic nutrition requires the scientific and practical application of these principles in the rationale of the treatment or alleviation of clinical disorders by dietary techniques.

To the nurse the practical application of the science of nutrition is a matter of day-to-day experience. In her work, the nurse has many opportunities of influencing people and helping them towards better eating habits.

In hospital the patient may often be amenable to suggestions about the choice of food to which formerly he would have paid no attention. In the community the nurse and health visitor play an important role in nutrition education. In spite of these important principles, Trooboff (1972) reports that 'nurses at all staff levels report negative reactions to their educational experience in nutrition and diet therapy' and 'the further the nurses are away from patients and the higher staff position they hold the higher the verbal priority they place on nutritional care. For the bedside-level nurse, nutrition has low priority'.

Unfortunately this dilemma continues to exist and the nutrition syllabus in nursing must endeavour to find a remedy. The nurse must have a thorough training in the principles of nutrition and an understanding of the modifications of the diet which are used in the treatment of many illnesses. This theory should, however, be related to practical experience gained in the ward where special diets are prescribed and in out-patient departments. In a college-based course, where students have day-release or block placings in hospital, it is particularly easy to arrange discussion groups and seminars on nutritional topics related to clinical experience.

The student nurse should also be introduced at an early stage in training to the concept of the team approach to the nutritional care of the patient. She should understand not only the role of the dietitian but also appreciate her background training. Joint projects and discussions of nursing, medical, dietetic and other paramedical students on nutrition can be of invaluable assistance. If students from different disciplines learn to work together during training they should be able to play a more effective part in the health team when they leave college.

In the integrated dietetic course, co-ordination and communication play an important role in the teaching of nutrition and therapeutic nutrition. The dietetic student may study as many as fourteen subjects in 4 years, in comparison to the five or six subjects taken by an honours graduate at university. If the student is to gain a thorough training all these subjects must be related, in general, to the main subject areas of the sciences, medicine, nutrition, social science and food services, and, in particular, to nutrition and dietetics. Co-ordinated lectures and practicals (if possible with team teaching) should be devised to enable the student to relate all aspects of the course.

The importance of communication in nutrition education has been emphasized 
by the report Dietitians of the Future by the Working Party of the Dietitians Board (1975). Nutrition teaching aids play an important part in communication, not only in lectures but also in student projects. There are many films available on nutritional topics and more groups are now making their own: an excellent example is 'In Place of the Sun' which was made by Glasgow Community Relations Council for use in nutrition education for immigrants.

Less expensive and of more practical use in the college setting is the videotape. A 'Portapak' unit with a black-and-white camera can be used without any special lighting for videotapes such as 'The Work of the Hospital Dietitian'. Students, with help, can also make their own tapes as part of a group exercise in communication.

Many tape-slide sets are now available which are of particular interest to dietitians. The Medical Recording Service Foundation have tapes which include the dietary aspects of diabetes, diverticulitis, renal disease and the coeliac condition. Teaching Aids at Low Cost (TALC) and Camera Talks Ltd provide tape-slide sets on malnutrition, nutrition and food hygiene. A synchronized tape-slide set can be made in college for the cost of the raw materials and is of particular value (especially with a back-up question book) for tutorial and remedial work. Students could also make tape-slide sets as group projects on topics such as 'Nutrition for Hospital Cooks'. The overhead projector, especially if portable, for outside lectures is another 'tool' which is relatively cheap and allows students to prepare their own transparencies.

Increasing use is now being made of the computer in nutrition education. Computer-Assisted Instruction (CAI) (Wade \& Thiele, I973) is an automated technique for presenting information to a student, asking questions and then giving more information based on the response. The college does not require to have a computer on the premises. An 'on-line' system can be operated either by direct line or through the telephone system. This has the advantage that the student is in 'live' communication with the computer via a terminal. A welldesigned program can allow the student to react in the light of results or 'interact' with the computer. One such program has been discussed by Hopkinson \& Lawrence (1974) and is called DIET. It is a statistical package which offers an analysis of the nutritional content of items of food chosen by the student. Costing exercises can also be undertaken. Programs such as DIET can offer realism to the learning situations and reinforce the teaching of nutrition as well as adding to the student's appreciation of the uses and limitations of the computer in everyday life.

Another aspect of communication in the dietetic course is that imparting a knowledge of nutrition is not enough: the practical application of the knowledge must be encouraged. Theory only, and overenthusiastic application of theory, sometimes leads to misunderstanding and often results in impractical suggestions. The dietitian must use language which is meaningful to the patient or client e.g. the food and function approach rather than the nutrient concept. If possible reality-orientated learning experiences must take place during the college training. This is achieved through student involvement in the profession, society and the 
community. Visiting lecturers are particularly important in preparing the student for work in the profession after training.

An introductory course in communication is important: this includes lectures on verbal behaviour (the communication model, importance of knowledge of both dietitian and client, position in the socio-cultural system) and non-verbal behaviour (eye contact, position in interview, gestures, facial expressions, role of the uniform) and also explains techniques used in controlling an interview and in coping with the client with special problems. When a student has completed a short lecture course in communication, design and the use of audio-visual aids, a role-playing exercise in the diet therapy practical can be undertaken. Heathcote, working in drama education at Newcastle University, has conducted much research in roleplaying which can easily be applied to other disciplines. The student should then have sufficient confidence to give talks on nutrition to groups outside college (slimming clubs, senior citizens). Voluntary work in the community and outside visits to hospitals, childrens' homes and community centres should also be encouraged.

\section{Conclusions}

In addition to providing sound academic knowledge at a level appropriate to different types of course, the creation of attitudes of mind and habits of thought is also considered to be of particular importance. It cannot be assumed that knowledge of nutrition will ensure good food habits: their development is a far more subtle process. Thus evaluation of the teaching programmes described is a daunting, if not impossible task. Academic competence may be assessed with a fair amount of accuracy but other qualities could be assessed only with the greatest difficulty, if at all. In any event, results should be judged on a long-term basis when students have had the opportunity to practice their professional expertise, rather than on completion of their college courses.

\section{REFERENCES}

Hopkinson, L. E. \& Lawrence, D. (1974). Housecraft 47, no. 6, 168.

Hotel, Catering and Institutional Management Association (1974). Hotel Catering Institutional Mgmt Ass. F. no. 32, p. 5 .

Trooboff, R. C. (1972). F. Nutr. Education 4, 62.

Wade, C. W. \& Thiele, V. F. (1974). F. Nutr. Education 5, 246.

Working Party of the Dietitians Board (1975). Dietitians of the Future. London: Dietitians Board. 